\title{
H1N1dsight is a wonderful thing
}

\author{
Criticisms of the response of governments and of the pharmaceutical industry to the threat of the H1N1 epidemic are \\ wide of the mark.
}

$T^{\mathrm{t}}$ he pandemic of influenza strain H1N1 has not yet manifested itself as the pestilence of biblical proportions that many had anticipated. According to the World Health Organization (WHO), swine flu is present in 212 countries and, to mid-February, has caused nearly 16,000 deaths worldwide. This is substantially lower than the death toll for seasonal influenza, which the US Centers for Disease Control (CDC) puts at around 30,000 a year in the United States, and a hundredfold lower than some initial estimates suggesting that one million deaths might be expected across the population of developed nations. The lack of virulence of H1N1 has left many countries with a stockpile of unused H1N1 vaccine. This is now prompting accusations that the WHO was guilty of scaremongering, with the complicity of drug companies. In reality, there's no reason to think that the WHO or drug companies should or could have acted differently. And the fact that a much larger proportion of the world's population is now immune to $\mathrm{H} 1 \mathrm{~N} 1$ than before the pandemic represents a great step forward in protecting the health of the world's population.

One downside of the relative mildness of H1N1 is that European governments now find themselves with vaccine stockpiles and are looking to trim their orders: Germany cancelled $30 \%$ of its order for GlaxoSmithKline (GSK)'s Pandemrix; the French health minister, Roselyne Bachelot, has cancelled 50 million doses; and the Belgian government has cancelled around a third of its 12.6 million-dose order. The UK has not bought up an option it had on vaccine from Baxter, and it is currently sitting on a vaccine stockpile of around 20 million doses with the prospect of buying another 30 million from GSK under a contract that is not reversible. The US government, too, has a huge vaccine stockpile because only 61 million US citizens have been vaccinated.

All this has created a finger-pointing environment in which governments are now being called to task for overreacting to the threat from swine flu. On December 18, a Socialist representative in the German Bundestag, Wolfgang Wodarg, and 13 other European national parliamentarians signed a motion claiming that "pharmaceutical companies have influenced scientists and official [public health] agencies" leading them to "squander tight health care resources [on] inefficient vaccine strategies and needlessly exposed millions of healthy people to the risk of unknown side-effects of insufficiently tested vaccines." This motion resulted in a hearing at the end of January convened by the Parliamentary Assembly of the Council of Europe to discuss the issue of "fake pandemics" (as the parliamentary group describes it).

These events raise several issues. It is disturbing that a rogue politician with a good sense of the zeitgeist can create such mischief for the WHO and drug industry, despite virtually no evidence of wrongdoing. Wolfgang Wodarg was the prime mover behind the fake pandemic outcry. He is a physician and a self-proclaimed expert in lung disease, who left medical practice in 1994. Back in August 2009, early in the swine flu outbreak, he was already talking up the possible side-effects of the vaccine. Wodarg has a history of dubious positioning with respect to biotech. Back in 2005, for instance, he was responsible for a report to the European Parliament on genetically modified organisms (GMOs) that called for stricter regulation of labeling, liability, good farming practice and GMO-free zones. The fact that the media continue to give credence to his kind ought to trouble the life science industry.

Beyond the machinations of antibiotech gadflies, however, there are more serious matters. Deeper reflection suggests that it would have been very difficult both politically and economically for any developed nation's government not to have invested significantly in vaccine and flu drugs.

Faced with the certainty of a new influenza virus to which a large proportion of the world's population was immunologically naive, and the uncertainty of the predictive epidemiological models, governments had little political choice but to act, anticipating something close to the worst case scenario. And the options they had at hand were somewhat limited.

Closing national borders is an option, although this is increasingly difficult given the volumes of travel and international trade that characterize our global village.

Another option is to close schools. Although this would restrict spread, it comes with a substantial cost. In September 2009, a report from the Brookings Institution found that closing all schools in the United States for four weeks might cost between $\$ 10$ billion and $\$ 47$ billion in parent absenteeism from work. A Swedish study published in the same month (Eurosurveillance 14, 5-11, 17 September 2009) showed that even without school closure, work absenteeism would represent a substantial economic burden as workers became ill themselves or took time from work to tend sick children. The authors estimated that vaccination against pandemic H1N1 influenza would be highly cost-effective, saving $€ 250$ (\$340) million. Other economic forecasters painted still gloomier pictures; in late 2009, the World Bank estimated that a worldwide pandemic could wipe out $0.7-4.8 \%$ of global gross domestic product.

Thus, it is difficult to conclude, even now, that governments that bought into preventative strategies for $\mathrm{H} 1 \mathrm{~N} 1$ made the wrong decision. Although the nature of the threat may have been overstated, the WHO, CDC and other authorities had little scientific evidence at the beginning of the H1N1 pandemic to discount the most dire predictions of fatalities.

The only question that remains is whether the purchase of vaccine orders by different countries should be better coordinated on an international scale. At the moment, different nations essentially compete with one another to grab a share of the vaccine supply from manufacturers. But is it justifiable that those nations that widely overestimate their demandpresumably taking supply away from other countries — can then return their stockpile to the drug companies that they contracted to supply vaccine in the first place? 